\section{Prolegómenos}

Derecho y Valores
Prolegómenos. Derechos y Valores

ISSN: 0121-182X

derechos.valores@umng.edu.co

Universidad Militar Nueva Granada

Colombia

Savaris, José Antonio

GLOBALIZACIÓN, CRISIS ECONÓMICA, CONSECUENCIALISMO Y LA APLICACIÓN DE LOS DERECHOS ECONÓMICOS, SOCIALES Y CULTURALES (DESC)

Prolegómenos. Derechos y Valores, vol. XV, núm. 30, julio-diciembre, 2012, pp. 21-44

Universidad Militar Nueva Granada

Bogotá, Colombia

Disponible en: http://www.redalyc.org/articulo.oa?id=87625443002

Cómo citar el artículo

- Número completo

- Más información del artículo

Página de la revista en redalyc.org

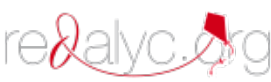

Sistema de Información Científica

Red de Revistas Científicas de América Latina, el Caribe, España y Portugal

Proyecto académico sin fines de lucro, desarrollado bajo la iniciativa de acceso abierto 


\title{
GLOBALIZACIÓN, CRISIS ECONÓMICA, CONSECUENCIALISMO Y LA APLICACIÓN DE LOS DERECHOS ECONÓMICOS, SOCIALES Y CULTURALES (DESC)*
}

\author{
José Antonio Savaris**
}

Fecha de Recibido: 21 de octubre de 2012

Fecha de Aprobado: 13 de noviembre de 2012

Artículo de Reflexión

Forma de citación: Savaris, J. A. (2012). Globalización, Crisis Económica, Consecuencialismo y la aplicación de los Derechos Económicos, Sociales y Culturales (DESC). Revista Prolegómenos. Derechos y Valores, 15, 30, 21-44.

\begin{abstract}
Resumen
Este trabajo tuvo como objetivo investigar el grado en el que las decisiones judiciales de los derechos económicos, sociales y culturales son influenciadas por sus consecuencias económicas. El documento sostiene que la globalización económica es una variable importante en lo que respecta a las distintas crisis económicas nacionales que han visto el mundo occidental. Por su parte, las crisis económicas que influyen en las decisiones judiciales en materia de derechos económicos, sociales y culturales, lo que lleva a un razonamiento judicial restrictivo del gasto social, que afecta a estos derechos en nombre de una supuesta maximización del bienestar social. Por último, el artículo propone la tesis de que, efectivamente, existe un espacio posible para el consecuencialismo judicial. Sin embargo, desde el punto de vista de la teoría jurídica, el consecuencialismo judicial posible y necesario es lo que lleva a juicio a guiarse por las consecuencias que reafirmen las bases axiológico-normativa del ordenamiento jurídico de la protección social y no, fundamentalmente, sus efectos económicos.
\end{abstract}

\section{Palabras clave}

Consecuencialismo, crisis económica, derechos económicos, sociales y culturales globalización.

* Agradezco a la Maestra Marcela Narváez Botero por la ayuda con el trabajo de traducción del presente texto al idioma español.

** Juiz Federal no Brasil. Doutor em Direito da Seguridade Social (Universidade de São Paulo - USP). Professor do Curso de Mestrado e Doutorado da Universidade do Vale do Itajai - UNIVALI. Presidente de Honra do Instituto Brasileiro de Direito Previdenciário. Coordenador do Curso de Pós-Gradução em Direito Previdenciário e Processual Previdenciário da Escola da Magistratura Federal do Paraná - ESMAFE-PR. currículo vitae: http://lattes.cnpq.br/7321974072296298. URL da Homepage: www.joseantoniosavaris.com.br. 


\title{
GLOBALIZATION, ECONOMICAL CRISIS, CONSEQUENTIALISM AND APPLICATION OF ECONOMICAL, SOCIAL, AND CULTURAL RIGHTS
}

\begin{abstract}
This work has for objective establishing to which degree judicial decisions regarding economical, social and cultural rights are influenced by their economical consequences. The article sustains that economic globalization is an important variable related to the diverse national economical crises the occidental world has witnessed. In this way, these economical crises end up influencing the judicial decisions regarding economical, social and cultural rights, leading to a judicial rationing of social expenses, affecting these rights in the name of a supposed maximization of social welfare. Lastly, the article offers the argument that there really is a possible space for judicial consequentialism. However, from the perspective of theoretical law, the possible and needed judicial consequentialism is the one who leads judicial decisions towards the consequences that reaffirm the axiological-normative fundaments of the juridical system and not, fundamentally, the economical effects.
\end{abstract}

\section{Keywords}

Consequentialism, Economical Crisis, Economical, Social and Cultural Rights, Globalization.

\section{GLOBALIZAÇÃO, CRISE ECONÔMICA, CONSEQUENCIALISMO E APLICAÇÃO DOS DIREITOS ECONÓMICOS, SOCIAIS E CULTURAIS}

\begin{abstract}
Resumo
O presente artigo teve como finalidade investigar em que medida as decisões judiciais em matéria dos direitos econômicos, sociais e culturais são influenciadas por suas conseqüências econômicas. O artigo sustenta que a globalização econômica é uma importante variável no que se relaciona às diversas crises econômicas nacionais que tem testemunhado o mundo ocidental. De sua parte, as crises econômicas acabam influenciando as decisões judiciais em temas dos direitos econômicos, sociais e culturais, conduzindo a um raciocínio judicial restritivo de despesas sociais, afetando-se estes direitos em nome de uma suposta maximização do bem-estar social. Por fim, o artigo oferece o argumento de que há, realmente, um espaço possível para o consequencialismo judicial. Nada obstante, na perspectiva da teoria do direito, o consequencialismo judicial possível e necessário é o que leva à decisão judicial a orientar-se pelas conseqüências que reafirmam os fundamentos axiológico-normativos do sistema jurídico de proteção social e não, fundamentalmente, os seus efeitos econômicos.
\end{abstract}

\section{Palavras-chaves}

Consequencialismo, Crise econômica, Direitos Económicos, Sociais e Culturais, Globalização 


\section{INTRODUCCIÓN}

La clásica división de los derechos humanos entre civiles y políticos, de un lado, y derechos económicos sociales y culturales, de otro, tenía como uno de sus fundamentos la idea de que la satisfacción de estos últimos (derecho a determinadas prestaciones), por el hecho de estar condicionada a una acción estatal positiva, implicaría necesariamente la designación de recursos públicos. De forma diferente, en la medida en que el ejercicio de los derechos civiles y políticos (derechos de defensa o de libertad) reclamaría la abstención de los poderes públicos no generarían reflejos presupuestarios.

De modo paradigmático, los trabajos de Holmes y Sunstein, y de Abramovich y Courtis demostraron de forma suficiente el equívoco de la premisa anteriormente expuesta. Los primerosargumentaron que la garantía y el ejercicio de cualquier derecho exigen la asignación de recursos públicos (Holmes \& Sunstein, 2000). Los últimos, consiguieron evidenciar que la estructura de los derechos civiles y políticos, así como la de los derechos económicos, sociales y culturales, se caracteriza como un complejo de obligaciones negativas y positivas por parte del Estado (Abramovich \& Courtis, 2002).

A pesar de la importante contribución de los anteriores autores, persiste el pensamiento de que los derechos económicos y sociales cuestan más que los derechos civiles y políticos, porque, igualmente, se valen de las estructuras administrativas que garantizan los derechos de defensa (generadoras de gastos institucionales), pero además requieren la prestación de servicios o pago de valores ut singuli (Lopes, 2008, p. p. 177; Silva, 2012).

Asociar la idea de implementación de los derechos sociales a la de aumento de gastos sociales se hace entonces inevitable. Desde la perspectiva económica, los derechos sociales serían, de este modo, derechos inconvenientes ${ }^{1}$.

1 Una interesante nota de Hugh Heclo, citada por Esping Andersen, expresa que el welfare state parece haber sido destinado a estar en crisis a partir de su
A partir de la década de 1980, las interacciones transnacionales alcanzaron una dramática intensificación "desde la globalización de los sistemas de producción y de las transferencias financieras, la diseminación a escala mundial de información e imágenes a través de los medios de comunicación, a los desplazamientos en masa de personas, sea como turistas, sea como trabajadores migrantes o como refugiados" (Santos, 2005, p. 25). Si bien es cierto que la globalización manifiesta relaciones sociales de naturaleza económica, política y cultural, todas sus dimensiones se encuentran afectadas por las imposiciones del consenso neoliberal (Santos, 2005, p. 27 y 31) y sus implicaciones: "La nueva pobreza globalizada no resulta de la falta de recursos humanos o materiales, sino del desempleo, de la destrucción de las economías de subsistencia y de la minimización de los costos salariales a escala mundial" (Santos, 2005, p. 35).

La cuestión que se propone analizar el presente trabajo, ampliamente fundamentado en textos anteriores del autor, es la de cómo la coyuntura económica impuesta por la globalización afecta la aplicación judicial de los derechos económicos, sociales y culturales. Ese debate pone en discusión el empleo del argumento consecuencialista en la aplicación judicial de esos derechos humanos. En otras palabras, se propone investigar si, desde la perspectiva de la teoría jurídica contemporánea, las decisiones judiciales pueden o deben incluir un componente consecuencialista. Más específicamente, se indaga sobre la corrección de la aplicación judicial orientada a partir de los

primer día. Visualizando una larga secuencia de crisis del welfare state, Andersen acota que en los años 50, el ataque provenía de la derecha y de economistas preocupados con el rápido crecimiento del sector público que sofocaría el mercado; una década después, el péndulo se inclinó hacia la izquierda, que veía ostensiva injusticia social en todos los lugares, al mismo tiempo en que el welfare state fue declarado completo; al final de los años 70 e inicio de los años 80 se llega a una tercera crisis, con el surgimiento del desempleo, difundiendo exceso de sobrecarga estatal de demandas y responsabilidades, con la idea de la sociedad ingobernable (Esping-Andersen, 1999, p. 2). 
efectos económicos, particularmente en materia de derechos económicos, sociales y culturales. Más que eso, se puede decir que el núcleo del presente trabajo guarda relación con el análisis de la adecuación o no de decisiones consecuencialistas cuando se trata de la aplicación judicial de esos derechos.

Con ese propósito fundamental, inicialmente se hizo una articulación con la fundamentación moral de los derechos económicos, sociales y culturales. La incursión en el campo de la moralidad política tiene dos importantes funciones para el desarrollo del presente estudio. De un lado, reafirma la esencialidad de esos derechos como elementos indispensables para la existencia digna, el desarrollo humano y la integración social. Por otro lado, contribuye como insumo teórico fundamental a la tesis consecuencialista en la aplicación judicial de los derechos económicos, sociales y culturales.

A continuación, se analiza la sinuosa relación entre globalización económica y afirmación de los derechos sociales, y de cómo una coyuntura económica crítica puede no sólo orientar procesos de reformas restrictivas de derechos, como igualmente la propia aplicación del Derecho, principalmente porque la actual metodología contemporánea se revela permeable a la ética consecuencialista de perfil económico-utilitarista.

Finalmente, después de lanzar reservas críticas a la aplicación judicial consecuencial-utilititaria-economicista, el presente texto ofrece una propuesta para lo que se considera el espacio posible, $e$ incluso indispensable, para el consecuencialismo jurídico en la solución de problemas vinculados a los derechos económicos, sociales y culturales.

\section{FUNDAMENTOS MORALES DE LOS DERECHOS ECONÓMICOS, SOCIALES Y CULTURALES (DESC)}

La evaluación de la teoría política normativa liberal-igualitaria, la justicia de orden social y política de una sociedad democrática presupone el compromiso del Estado con los derechos que consolidan las libertades, oportunidades y los recursos necesarios para que cada persona pueda "intentar hacer de su vida - la única que le fue concedida para vivir - algo significativo y que valga la pena vivir" (Vita, 1993, p. 11).

La justificación moral de los derechos humanos fundamentales puede partir de la noción de igualdad humana fundamental. Se trata de una interpretación universalista que se justifica, no por imponer una determinada concepción de una vida buena de ser vivida por todos los seres humanos, sino por el argumento de que podemos tener una nítida idea de aquello que degrada o transforma la vida humana desgraciada en cualquier lugar2.

De esa noción del valor intrínseco igual de los seres humanos deriva la tesis de que todas las personas, independientemente de la suerte que la naturaleza y la sociedad le reservaron al nacer, son portadoras de determinados derechos cuyo respeto presupone la legitimidad de la autoridad política en una sociedad ${ }^{3}$. "Más específicamente, de la tesis del valor intrínseco de todas las vidas humanas emerge el reconocimiento de que la "libertad de bienestar" - y no sólo la "libertad de

2 Como, por ejemplo, "a pobreza extrema, o trabalho escravo, o trabalho infantil, a mutilação genital feminina, a proibição - imposta a muitas mulheres no mundo - de freqüentar a escola, trabalhar e ter acesso a cuidados médicos, a prisão, tortura e execução de dissidentes $e$ opositores políticos, as práticas de 'limpeza étnica' e de estupro em massa de mulheres em conflitos étnicos" (Vita, 2008, p 33)

3 Aclárese: La creencia en el valor intrínseco igual de los seres humanos se expresa por la clásica formulación kantiana de que mientras otras cosas tienen un precio o un valor para las personas, solamente la vida humana está por encima de cualquier precio, o sea, tiene dignidad; y aquello que tiene dignidad no puede ser tratado como medio sino siempre como un fin en sí mismo (Kant, 1980, p. 134 y 141). Entonces, "quando sustentamos que todos os seres humanos têm certos direitos, é que a vida, o corpo, a propriedade, a liberdade e o bem-estar de cada homem não podem ser discricionariamente dispostos ou vistos como meros instrumentos a serviços dos fins e objetivos de outros" (Vita, 1993, p. 9-10). 
agencia" - de cada persona tienen igual valor" 4 (traducción nuestra ${ }^{5}$.

El reconocimiento de los derechos económicos y sociales de todas las personas implica la afirmación de su humanidad como un fin en sí mismo. La garantía de políticas públicas destinadas a hacer frente a las necesidades más elementales de los individuos constituye el presupuesto de una existencia digna, del libre desarrollo de la personalidad y de la integración social.

Desde una perspectiva histórica, el reconocimiento y el progresivo ejercicio de los derechos económicos y sociales se suceden como la genuina solución para la cuestión de la sustentabilidad social. La cohesión social y la preservación de lo humano se encontraban bajo la amenaza de los maléficos efectos del culto a la libertad, igualdad formal y acumulación del capital, que conformaban la ideología del Estado de Derecho (Liberal).

4 Esa categorización fue sustentada originalmente por Amartya Sen (1985). La libertad de agencia, que los derechos civiles y políticos tradicionales tienen como objetivo asegurar, consiste en la libertad de hacer elecciones y de actuar de acuerdo con las propias convicciones y concepción del bien. Por su parte, la libertad de bienestar, forma de libertad que los derechos económicos y sociales tienen como destino asegurar, se relaciona con las oportunidades efectivamente disponibles para que una persona escoja entre diferentes actividades y formas de vida, o sea, con aquello que las personas pueden razonablemente exigir a la sociedad en que viven para tener la posibilidad de hacer algo valioso de sus vidas (Vita, 1993, p. 12). Se debe comprender que la libertad de bienestar también se preocupa con la capacidad de los individuos de realizar elecciones: "ser capaz de escoger entre actividades y formas de vida distintas supone que ciertos beneficios estén asegurados a todos (...) y supone la existencia de un abanico mínimo de alternativas aceptables para el agente. Sería, en el mejor de los casos, una manifestación de cruel humor negro preguntarle a un niño de la calle que pide limosna en un cruce de São Paulo por qué él no 'escoge' otra forma de vida para sî" (Vita, 1993, p. 12).

5 Las traducciones para el idioma español de las transcripciones hechas en el curso del presente trabajo tienen todas las mismas referencias, siendo de nuestra libre traducción.

6 El primer siglo de la sociedad capitalista fue testigo de las deshumanas condiciones de trabajo a que eran sometidos los trabajadores empleados en las industrias
Solamente la percepción de cuánto la Revolución Industrial representó en términos de amenaza a la vida y al bienestar del país que la engendró, permite la compresión del surgimiento de los derechos sociales como instrumento de socorro a las víctimas de la transformación impuesta por ella. De hecho, el vasto movimiento de progreso tecnológico y económico hizo caer sobre Inglaterra una avalancha de desarticulación social:

Antes que el progreso hubiera ido suficientemente lejos, los trabajadores ya se amontonaban en nuevos locales de desolación, las así llamadas ciudades industriales de Inglaterra; la gente del campo se deshumanizaba en habitantes de tugurios; la familia estaba a camino de la perdición y grandes áreas del país desaparecían rápidamente bajo montañas de escoria y residuos vomitados por los $<<$ molinos satánicos >>" (Polanyi, 2000, p. 58) 7 .

y las privaciones sufridas por el ejército industrial de reserva. El desarrollo de la industria de la lana constituía un importante recurso para Inglaterra, conduciendo al establecimiento de la industria textil, el vehículo de la Revolución Industrial. Por otro lado, colocaba al pueblo en desgracia. "O tecido social estava sendo destruído; aldeias abandonadas e ruínas de moradias humanas testemunhavam a ferocidade da revolução, ameaçando as defesas do país, depredando suas cidades, dizimando sua população, transformando seu solo sobrecarregado em poeira, atormentando seu povo e transformando-o de homens e mulheres decentes numa malta de mendigos e ladrões" (Polanyi, 2000, p. 53). Como observa el mismo historiador, aunque eso sucediera apenas en determinadas áreas, tales puntos negros amenazaban fundirse en una catástrofe uniforme.

7 Polanyi denomina $<<$ molino satánico $>>$ al espantoso progreso de los instrumentos de producción que, permitiendo una economía de mercado, tuvo como efecto una catastrófica desarticulación en la vida de las personas comunes, mecanismo este que "trituró a los hombres transformándolos en masa", destruyendo el antiguo tejido social e intentando, sin éxito, una nueva integración hombre-naturaleza (2000, p. 51). No está de más observar que "Escritores de todas as opinióes e partidos, conservadores e liberais, capitalistas e socialistas, referiamse invariavelmente às condições sociais da Revolução Industrial como um verdadeiro abismo de degradação humana", de tal sorte que "a história da civilização do século XIX consistiu, na sua maior parte, em tentativas de proteger a sociedade contra a devastação provocada por esse mecanismo (2000, p. 51). 
De hecho, como consecuencia de la Revolución Industrial, en el Siglo XIX, se verificó la grave repercusión de contingencias que le impedían a una persona obtener los recursos por su propia fuerza. Estas situaciones de riesgo de subsistencia y los estados de necesidad consecuentes, pasaron a ocupar el centro de la agenda política de las sociedades europeas. Se hacía indispensable la intervención estatal para conciliar los intereses y necesidades de los capitalistas y de la clase trabajadora ${ }^{8}$.

La constitucionalización de los derechos económicos y sociales no tardaría, como lo muestran la Constitución Mexicana (1917) y la República de Weimar (1919). No obstante, fueron las grandes desilusiones de la modernidad - la de la economía capitalista, frente a la profunda crisis económica, la del derecho, frente a la tragedia nazi-fascista - que no dejaron más alternativas a la acción política occidental sino evolucionar hacia un Estado Democrático Constitucional que, reconociendo en la protección de la dignidad humana el punto de partida y el objetivo fundamental de nuestra civilización, consagra derechos fundamentales, inclusive $y$, especialmente, los sociales ${ }^{9}$.

Por tanto, los derechos económicos, sociales y culturales nada le deben en términos de fundamento a los derechos civiles y políticos ${ }^{10}$. $Y$ no se trata apenas de una importancia igual entre derechos, generada por el reconocimiento institucional y su incorporación como derechos

8 Para una reflexión sobre el surgimiento de los sistemas de protección social en nuestra cultura occidental, v. la contribución de Paulo Márcio Cruz (2005, p. 11-92).

9 Sobre el tema de la dignidad de la persona humana, verificar la valiosa contribución de Ingo Sarlet (2005), que organiza y articula texto que integra conjunto de importantes trabajos desde la perspectiva jusfilosófica.

10 Con razón Vita, cuando expresa la inexistencia de primacía entre esos derechos en la perspectiva de la teoría moral: "Não há porque supor, portanto, que os direitos de autonomia e de liberdade individuais devam ser considerados mais genuínos ou prioritários que os direitos de bem-estar sócio-econômico. Uns e outros são justificados pela crença fundamental no valor intrínseco do bem-estar humano" (1993, p. 14). constitucionales fundamentales en un Estado Democrático de Derecho. Antes bien, en la medida en que la naturaleza de esos derechos es primordialmente moral, los mismos, igualmente, ocupan un lugar importante en la moralidad política de una democracia, estableciendo razones perentorias para la acción política (Vita, 1993, p. 30) o jurídica ${ }^{11}$.

\section{DERECHOS SOCIALES, GLOBALIZACIÓN Y CRISIS ECONÓMICA}

Fundamentada en la preeminencia del mercado (educación, seguridad social y sistemas médicos privados, privatizaciones de empresas públicas, delegación de servicios públicos), la hegemonía neoliberal promulga el discurso ideológico de equilibrio fiscal y riguroso control de gastos públicos, buscando la expansión del espacio de libre explotación económica por la iniciativa privada y un ambiente institucional propicio para garantizar el retorno del capital invertido.

Con el surgimiento de la globalización económica y sus trazos de eliminación de las restricciones y obligaciones locales del capital y la resultante extraterritorialidad de las principales fuerza económicas, los Estados son llevados a subordinar el espacio político a las exigencias y los preceptos de la razón tecnocrática e instrumental, entre los cuales se encuentra el postulado de austero control de las cuentas públicas (principio de los

11 La justiciabilidad de los derechos económicos, sociales y culturales, así entendida la posibilidad de buscarse judicialmente la satisfacción de esos derechos en caso de ausencia o inadecuación de políticas públicas dirigidas específicamente hacia su realización, deriva de su naturaleza jusfundamental y de su fuerte fundamentación moral. Aunque existan diversas objeciones para la aplicación jurídica de los derechos sociales, económicos y culturales, como por ejemplo la ausencia de legitimidad democrática y de capacidad institucional (en términos de condiciones técnicas para la realización de políticas públicas) o los límites impuestos por la escasez de recursos, la justiciabilidad de un derecho fundamental, por lo menos en determinado grado, es la suposición de su existencia. 
presupuestos equilibrados) ${ }^{12}$. Es la autonomía de lo político comprometida por lo económico (Tejada, 2011, p. 153; Morais, 2006, p. 22; Esping-Andersen, 1999; Esping-Andersen, 1996, p. 2; Pierson, 2001, p. 80).

A partir de la globalización, "la inestabilidad económica aumentó y, con la permanencia del estado de emergencia económica, el apelo a los poderes de emergencia para sanar las crisis económicas pasó a ser mucho más utilizado" (Bercovicci, 2004, p. 179). Por esa razón los derechos sociales y, más específicamente, los derechos que corresponden a deberes estatales positivos de protección social (educación, salud, asistencia y seguridad social) son el campo de batalla de medidas de emergencia y de la adversidad constitucional en varios Estados. Ya había sucedido con los derechos sociales de la Constitución de Weimar (1919) que, después de haber sido percibidos como simples expresiones políticas o como programa para el legislador, constituyeron el objeto principal de los decretos de emergencia desde 1930 (Bercovicci, 2004, p. 29).

Es necesario reconocer que los derechos sociales se encuentran gravemente amenazados por la globalización económica que tiende a mercantilizarlos (Tejada, 2011, p. 158) ${ }^{13}$. Es

12 Se debe comprender, en efecto, el importante significado de la globalización: "La globalización es producto, entre otras cosas, del engranaje económico (ter), político (poder), ideológico (conocimiento) y jurídico (orden) que afianzan y homogenizan modelos universales: en este sentido, existen en lo económico monedas sin reservas pero sólidas comparadas con las divisas de los países en vías de desarrollo, en lo político, las potencias del Norte imponen a través de sus instituciones las agendas políticas para los estados menos fuertes, en lo ideológico prevalece la mentalidad productiva, consumista y neoliberal y en lo jurídico se acentúa la necesidad de crear instancias internacionales para administrar justicia a los nacionales de cualquier estado" (Cortés, 2010, p. 71).

13 A la final, "La lógica económica de la globalización resulta incompatible con la lógica política y axiológica del Estado Social. En esta pugna, los agentes económicos de la mundialización pueden imponerse sobre los Estados Sociales que, en última instancia, deben recurrir a aquellos para financiarse" (Tejada, 2011, p. 158). de hecho intuitivo que, en el contexto de la globalización - y de la "permanencia del estado de emergencia económica", los derechos sociales deban ser restringidos ${ }^{14}$.

\section{DERECHOS HUMANOS Y LA TEORÍA MORAL CONSECUENCIALISTA-UTILITARISTA}

En su forma más pura y simple, el consecuencialismo es una doctrina moral, según la cual la acción correcta en una determinada situación es aquélla que produce el mejor resultado común, juzgado como tal desde un punto de vista impersonal que concede igual peso a los intereses de cada uno. La reflexión moral consecuencialista tiene como versión más familiar el utilitarismo el cual, en su forma clásica, dice que el mejor estado, dentro de las combinaciones posibles es el que muestra el mejor balance líquido agregado de placer humano, felicidad o satisfacción, es decir, es aquél que maximiza las utilidades totales o medias (Scheffler, 1988, pp. 1-20).

Originado a fines del siglo XVIII, el movimiento filosófico conocido como utilitarismo, moralismo británico o pensamiento radical, traduce el esfuerzo de evaluar y tratar el mundo a partir de un relativo encantamiento con la racionalidad humana que surgió con la visión Iluminista de mundo que caracterizó los siglos XVII y XVIII.

Aunque el utilitarismo es una teoría moral con muchas facetas, existe una idea central que permea a todas ellas, que es la de privilegiar la evaluación de las acciones en términos de su utilidad más que en términos de sus propiedades

14 En Brasil la década del 90 demostró algo para hacer - en términos de restricción de derechos sociales - en nombre de la seguridad económica y de la austeridad fiscal, sea por la fuerte influencia de la ideología neoliberal, sea por las amenazas de crisis económicas globales por esta ideología propagada (Savaris, 2008, pp. 339-337). Interesantes estudios de Paul Pierson (2001, pp. 80104; 1994) demuestran, por otra parte, las estrategias para la reducción de los costos políticos provenientes de reformas restrictivas de derechos sociales 
intrínsecas. De esta forma, los conceptos del bien son más básicos o prioritarios en relación con los conceptos de derecho y obligación. La idea atractiva del utilitarismo es, sin lugar a dudas, la importancia de la promoción del bienestar a través de varias formas.

Antes de la publicación de Una teoría de la justicia, de John Rawls, en 1971, el utilitarismo era la perspectiva dominante en la filosofía política de lengua inglesa. Con el surgimiento de la teoría de la $<<$ justicia como equidad $>>$, el liberalismo orientado a los derechos se hizo predominante en el mundo de la filosofía moral y política anglo-americana (Hart, 1979, pp. 77-98) ${ }^{15}$.

Si el consecuencialismo puro o radical fuera aceptado como la forma más apropiada de reflexión ética, no existiría ninguna atrocidad que no pudiera justificarse teniendo como base el estado de cosas más benéfico a ser alcanzado (Rawls, 1971, p. 27). El motivo es que se concibe la supremacía de una determinada visión del bien humano-que consiste, por ejemplo, en la máxima satisfacción posible de los deseos y de las aspiraciones individuales - sobre los principios de la justicia y del derecho. En una ética radicalmente teleológica, los derechos son instrumentales a aquella visión del bien humano, son instrumentos de la maximización del bien. De este modo, se le atribuye "un valor supremo a un determinado fin o concepción de la buena vida y subordina todo aquello que podemos considerar moralmente significativo - principios de justicia, derechos y deberes - para la consecución de ese fin" (Vita, 2000, p. 32).

15 La obra de John Rawls sacudió las bases de la teoría ética utilitarista, al evidenciar que la misma consideraba los derechos fundamentales de las personas, tanto como cualquier recurso material, como medios a ser afectados para que se produjera la máxima satisfacción colectiva, independientemente de la forma de distribución de la satisfacción. No hay espacio en el presente trabajo para profundizar el análisis de las críticas que el liberalismo orientado a los derechos lanzó a la teoría ética utilitarista. Un estudio mejor elaborado sobre las críticas lanzadas al utilitarismo desde la perspectiva de la filosofía política y de la filosofía del derecho (2011, pp. 46-55).
Efectivamente, la ética de la maximización del bien común vive en constante tensión con los derechos, pues no sólo admite, como exige, la violación de pretensiones justificadas como las de los derechos fundamentales, siempre que ello contribuya para el bien colectivo (Hoffe, 2003 p. 43) ${ }^{16}$.

Debido al hecho de no responder adecuadamente a las exigencias de justicia que fundamentan la protección de los derechos de los individuos, el utilitarismo debe ceder ante una construcción que promueva efectivamente tales derechos, aun cuando no sean considerados adecuados para la promoción de determinado ideal colectivo que corresponda a la satisfacción de las preferencias o intereses de la mayoría.

En tales condiciones, si no fuera por el carácter inmediatamente plausible y atrayente de la teoría moral utilitarista, impresionaría el argumento de que algunas de las principales alternativas metodológicas al positivismo legalista tienden a trasladarse justamente dentro de su cuadrante.

\section{APLICACIÓN JUDICIAL DEL DERECHO DE PERFIL CONSECUENCIALISTA}

A mediados del siglo XIX, en Alemania, la jurisprudencia de conceptos (Begriffsjurisprudenz) partía de la concepción del derecho como realidad socialmente "dada" o "puesta" y como unidad sistemática de normas generales, para buscar un derecho unitario y sistemático. Era la expresión máxima de la concepción formalista en la ciencia jurídica (Bobbio, 1995, p. 221).

La superación crítica del positivismo conceptual (legalista o aún analítico-lingüístico) tradujo a partir de la segunda mitad del siglo XIX el esfuerzo de diferentes escuelas metodológicas

16 Es cierto que no faltan réplicas utilitaristas sofisticadas, pero el punto es que ninguna de ellas deja de reverenciar el principado de la utilidad: la maximización del bien, gane el que gane, pierda el que pierda. 
que constituyen el surgimiento y la evolución de una actitud que deja de limitar la decisión judicial a la operación lógica concerniente a las conexiones entre los términos, expresiones o enunciados normativos de los materiales jurídicos (legislación o precedente).

Sin embargo, algunas de las principales corrientes teóricas y metodológicas que pretendían romper con el encantamiento científico-positivista de la subsunción se aproximaron decisivamente a una ética social utilitarista, comenzando por el utilitarismo social de Ihering en Alemania, y sus marcas en la jurisprudencia de intereses y en la jurisprudencia de valores, hasta culminar con su influencia en los juicios de ponderación de principios, de amplia aceptación en la dogmática constitucional del mundo occidental, principalmente, por su recepción de la teoría de la argumentación de Robert Alexy (2005).

Según Ihering, en el período tardío de su pensamiento, cuando la dialéctica jurídica "tuvo que ponderar las consecuencias de los conceptos y principios en juego, se decidió, esencialmente, por la adecuación práctica del resultado" (Larenz, 1997, p. 58).

Pero la ruptura del formalismo jurídico operada en la segunda mitad del siglo XIX por el substrato teórico de la Jurisprudencia de Intereses (interessenjurispudenz) no haría de la ciencia del Derecho más que un instrumento de lo que fuera socialmente útil, en un contexto teórico anti-individualista y de sobrevalorización de la prosperidad de la comunidad ${ }^{17}$.

17 Según la teoría social de Ihering, doctrina de línea confesadamente benthamiana y expuesta en su clásico Der Zweck im Recht (La finalidad del derecho), "todas as normas morais têm por finalidade a existência e prosperidade da sociedade" (2002, p. 110). El utilitarismo social de Ihering, embrión de la Jurisprudencia de Intereses, identificaba la moral con lo que es útil para la sociedad (a la conservación de la existencia social, en lo que se comprende el bienestar de la sociedad). Por eso, de acuerdo con el utilitarismo social, el derecho debe prestarse como instrumento de la autoconservación social y de los sentimientos de placer y bienestar que le son inherentes: "Tudo
En la perspectiva de la jurisprudencia de intereses, si la tarea del juez es complementar las normas jurídicas según juicios de valor, la tarea de la ciencia jurídica es facilitar esa difícil misión, previendo los vacíos, proponiendo complementaciones y formulando al juez las consideraciones decisivas (Heck, 1999, p. 72) ${ }^{18}$.

Esa ética consecuencialista puede accionar el proceso de toma de decisiones, independientemente de la estructura metodológica adoptada, siempre que exista espacio para el discurso racional argumentativo o juicios de ponderación de determinados intereses, valores o bienes para la determinación de la norma jurídica aplicable al caso concreto ${ }^{19}$.

De hecho, como reacción a la Escuela del derecho natural y al formalismo de la Escuela histórica alemana, "el derecho se convierte, en la escuela

o que é moral, quer objetiva, quer subjetivamente, tanto as normas morais quanto a atitude moral, tem por objetivo a prosperidade da sociedade. O imoral caracteriza-se, pois, por ameaçá-la ou prejudicá-la" (Ihering, 2002, p. 126).

18 Y en toda operación, en toda formación de conceptos, se debe intentar no perder de vista que el objetivo final de la actividad jurídica y de la resolución del caso concreto por el juez es la satisfacción de las necesidades de la vida, la satisfacción de intereses, sean materiales, sean ideales, presentes en la comunidad jurídica (Larenz, 1997, p. 65). Por otra parte, "como cada valoração, corretamente entendida, constitui una livre tomada de posição do sujeito valorante, tomada de posição que se dirige, sem dúvida, a u critério de valor, mas que não pode ser "causada" por ele, eis que, com introdução do conceito de valor, a simples consideração "causal" das normas jurídicas vem a ser efetivamente abandonada" (Larenz, 1997, p. 68).

19 Se parte siempre de la suposición de que en el proceso de toma de decisión jurídica la tarea del magistrado no se restringe a un raciocinio lógico-deductivo de aplicación del Derecho. Frente a la abertura de determinadas normas jurídicas, especialmente las constitucionales, y la inexistencia de plena regulación normativa, a veces las premisas a ser utilizadas para llegar a una solución para el conflicto no son acatadas sin mayores problemas, siendo necesario un mayor esfuerzo con relación a las razones del acto de decidir para que haya el efectivo convencimiento de todos los destinatarios de la decisión. 
utilitarista, en el instrumento de la política y de la economía; técnica de control social instaurada con el fin de obtener la maximización de los placeres o el incremento de la potencia colectiva del grupo" (Villey, 2003, p. 250). Y a pesar de las críticas dirigidas a la ética utilitarista, ella "parece insinuarse en todas las expresiones contemporáneas de la hermenéutica constitucional, a los dos lados del Atlántico" (Coelho, 2008, pp. 48-49) ${ }^{20}$.

Si la racionalidad del discurso de la decisión judicial (campo de la razón práctica) es meramente formal (ajena a los fundamentos axiológico-normativos del Derecho), porque asume una actitud instrumental o finalística (orientada a las consecuencias ajenas a esos fundamentos), las alternativas metodológicas que se presentan en contraposición al positivismo legalista se encuentran abiertas a la lógica de la instrumentalización del Derecho y de la funcionalización del actuar jurídico, una lógica propia del consecuencialismo utilitarista.

Consecuentemente, se entiende el modo por el cual una racionalidad finalística - vinculada a la ética consecuencialista - puede operar en el ejercicio de la jurisdicción constitucional, principalmente cuando las decisiones pueden afectar de modo decisivo los objetivos sociales, políticos o económicos identificados en determinada coyuntura histórica, y mostrarlos como siendo de importante realización.

En este contexto, también se comprende el papel relevante asumido por los estudios

20 A jurisprudência sociológica (sociological jurisprudence) de Roscoe Pound pode ser considerada como o movimento metodológico precursor desse instrumentalismo jurídico-tecnológico (Neves, 1993, p. 54). Mas não se deve minimizar a influência de Ihering na propagação da concepção funcional do Direito desde a segunda metade do século XIX. Com efeito, A visão funcional do Direito tornouse dominante por volta do fim do século XIX, após gradativa mudança de perspectiva impulsionada pelo empreendimento de Ihering (Perelman, 2004. p. 70). económicos en el área del Derecho ${ }^{21}$ y la fascinación que se percibe en una interdisciplinaridad que se propone dar un racional impulso de utilidad al fenómeno jurídico ${ }^{22}$.

Según el análisis económico, para la definición de reglas de conducta, el Derecho deberá considerar los impactos económicos decurrentes de estas reglas, la designación de los recursos y los

21 Los pioneros del nuevo análisis económico del Derecho fueron Ronald Coase y Guido Calabresi (Posner, 1983. p. 4). En su famoso artículo "The problem of social cost", publicado en el año de 1961 no Journal of Law and Economics, Coase se valió de diversas normas y casos jurídicos ingleses y, analisando la relación entre reglas de responsabilidad y destinación de recursos, demostró que las soluciones solamente se justificaban con referencia a un análisis de costo-beneficio y frente a su aptitud para el mejor destino de recursos. En el mismo año de 1961, Calabresi publicó, con objeto semejante, el artículo "Some thoughts on risk distribution and the law of torts", en el Yale Law Journal 70, 499, insertando el análisis económico en cuestiones jurídicas y refiriendo que un análisis jurídico adecuado presume el tratamiento económico del problema (Esos trabajos provocaron la fundación del movimiento denominado The Law and Economics, posteriormente desarrollado con la contribución de Richard Posner, Gary Becker e Henry Manne).

22 El análisis económico del Derecho tiene en el mercado el criterio de racionalidad $y$, en su eficiencia, el elemento justificador del Derecho. Parece importante relacionar el actual perfil del análisis económico del Derecho, difundido a partir de la década del 60 en Estados Unidos, con los fundamentos pragmáticos y consecuencialistas del Realismo Americano. Si el realismo desde Oliver Holmes se dirigía más hacia los hechos que hacia las normas, colocando énfasis en los efectos de las decisiones judiciales, el análisis económico del Derecho, también rompiendo con el formalismo, se proponía identificar en qué medida el common law se dirigía hacia los resultados que proporcionaban la maximización de la riqueza social. En la perspectiva del análisis económico del Derecho, la solución de los problemas jurídicos supone el estudio de las dimensiones económicas. La eficiencia económico-social de un sistema jurídico se presenta como problema fundamental del análisis económico. Y la pretensión del análisis económico se orienta también hacia el sistema de derecho codificado, donde es posible la formulación de reglas que adopten criterios que induzcan a las personas a buscar eficiencia de destinación (Sztajn, 1998, p. 28). 
incentivos que influyen sobre el comportamiento de los agentes económicos privados ${ }^{23}$.

No debe causar perplejidad que, en el ejercicio de su jurisdicción constitucional, el juez sea permeable a la orientación consecuencialista. Esto será más comprensible cuando, aún tratándose de derechos humanos económicos sociales y culturales, las decisiones consecuencialistas sean percibidas en un momento histórico-político de austeridad fiscal y de acuerdo con programas legislativos restrictivos de esos derechos.

\section{CRÍTICAS AL CONSECUENCIALISMO ECONÓMICO EN LA APLICACIÓN DEL DERECHO}

Es posible identificar el perfil consecuencialista (de naturaleza económica) de esas decisiones por el discernimiento de que ellas operan de modo evidente en una coyuntura económica crítica. Al final, es justamente ese el contexto histórico que permite observar, por un lado, la instrumentalización del Derecho con relación a finalidades sociales y políticas (mediante reformas restrictivas de los derechos sociales) y, por otro lado, la tarea jurídica como "técnica de gestión que pretende promover el óptimo desarrollo económico y social de la ciudad" (Neves, 1993, p. 60).

Es importante reconocer que los factores políticos, sociales y económicos tienen potencial para conducir al juez a considerar el impacto económico de sus decisiones - y orientarse por esta circunstancia ${ }^{24}$.

23 Para un análisis crítico del análisis económico del Derecho e su íntima relación con el consecuencialismo utilitarista en la aplicación jurídica del Derecho, v. nuestro (2008, pp. 213-227).

24 En la tarea hermenéutica de aclarar las condiciones en las que surge una comprensión, Hans George Gadamer rescata la importancia de reconocernos en una determinada situación hermenéutica. La conciencia de la situación hermenéutica supone el reconocimiento de que el intérprete es un ser incluido en la historia y que, por esa razón, agrega a su ámbito de visión el conjunto de experiencias traídas por la tradición. Eso significa que el intérprete, como un ser histórico, está
Cuando la argumentación jurídica es animada por apelaciones de orden moral o políticas, las decisiones judiciales en materia de derechos sociales se muestran más propensas a ser emitidas a partir de una concepción radicalmente consecuencialista, principalmente mediante la evaluación de los impactos de las decisiones judiciales sobre los presupuestos públicos.

Al sopesar principios constitucionales antagónicos en un caso concreto, la jurisdicción constitucional puede determinar la prevalencia del interés de preservación del equilibrio de las cuentas fiscales o el principio de la eficiencia económica (maximización de los recursos), mediante el no reconocimiento jurídico de derechos sociales.

El sistema jurídico brasileiro es claramente abierto al consecuencialismo jurídico, como se percibe por la aplicación de la técnica de modulación de los efectos temporales de las decisiones del Supremo Tribunal que declaran la inconstitucionalidad de ley o acto normativo, en los términos de las Leyes 9.868, de 10/11/1999, y 9.882, de 03/12/1999. La adopción de la doctrina prospectiva en la declaración de ineficacia de las leyes inconstitucionales, en vez de la tradición jurídica que reconocía la nulidad de la ley inconstitucional, con efectos ex tunc, presupone consideraciones sobre los resultados prácticos de las decisiones, principalmente las que se refieren a razones de seguridad jurídica y excepcional interés social.

En el ámbito de los derechos económicos, sociales y culturales, es posible encontrar decisiones del Supremo Tribunal Federal con inclinación consecuencialista - de origen económico-utilitarista (Savari, 2008). Envuelta en una atmosfera de crisis económica y preeminente necesidad de equilibrio de las cuentas públicas, la Corte Suprema brasileña, en materia de Previsión Social, llegó a negar la mejoría de las pensiones

sujeto a los efectos de los fenómenos históricos, los que son, por lo tanto, decisivos para la formación de sus prejuicios y, por consecuencia, para su comprensión de las cosas. Es lo que Gadamer denomina historia efectual (Gadamer, 2003, p. 396). 
por muerte, valiéndose, también, del argumento de la inexistencia de fuente de costeo previo, y que eso pondría en jaque el indispensable equilibrio financiero y de acción del sistema de previsión social-RE 415.454, juzgado en febrero de 2007.

Pocos meses después, el mismo Supremo Tribunal Federal consideraría legítima la Enmienda Constitucional 41/2003 en la parte que menguaba el contenido de la regla transitoria para jubilaciones de servidores públicos (ya gravemente afectados por una reforma anterior del sistema de seguridad social), bajo el argumento de inexistencia de derecho adquirido a régimen jurídico-ADI 3104 , juzgado en septiembre de 2007. Aún cuando se le atribuyera a la alteración normativa la inconstitucionalidad por afrontar valores como seguridad jurídica, protección de la confianza de los trabajadores y, aunque la cuestión haya sido solucionada en la perspectiva de la inexistencia de derecho adquirido a régimen jurídico, el análisis del Ministro Cezar Peluso, teniendo como eje las posibles consecuencias económicas de la decisión jurídica, muestra una línea de pensamiento que parece permear el raciocinio deductivo jurídico de algunas decisiones de la Suprema Corte:

No es sólo el problema de seguridad jurídica, el problema es también evaluar el costo y la viabilidad económica de ciertas prestaciones estatales [...] [Los problemas de la seguridad social y de la administración del sistema] pueden aniquilar los sistemas y hacer perder los propios derechos evidentemente adquiridos. Su Excelencia imagine una situación de caos - no diría estar próxima o lejana, mas concibo hipotéticamente que pueda un día llegar-, en la que fuera decretada la falencia práctica del sistema de seguridad social, a tal punto que el Estado no pudiera más responder por la jubilación de aquéllos que, hace tanto tiempo, dependen de ella para sobrevivir. ¿Cómo hacemos? ${ }^{25}$

25 Argumento deducido en el juicio de la ADI 3104/ DF (p. 176-177), realizado por el Plenario del Supremo Tribunal Federal, en el que fue relatora la
¿Esa conexión entre coyuntura económica y jurisdicción constitucional de los derechos económicos, sociales y culturales se daría apenas en los así llamados países en desarrollo o sería un fenómeno global? Aunque la respuesta a esta cuestión dependa de un análisis más detenido de otras variables incluidas en el proceso de la toma de decisiones judiciales, es posible reconocer que ese mecanismo (crisis económica - jurisdicción constitucional con interpretaciones restrictivas de derechos) opera de la misma forma en los asíllamados países centrales. A título ilustrativo, en el análisis que hace de la orientación de la Corte Constitucional italiana, Loris Iannuccilli sustenta que "Non a caso, il progressivo declino delle additive di prestazione, registrabile a partire dagli anni novanta, è concomitante y corrisponde alla crisi dello Stato sociale, indotta dall'agravamento delle difficoltà della finanza pubblica" (Iannuccilli, 2012, p. 11).

Alimentándose de las ciencias sociales, como la economía, la ciencia política y la sociología, el pensamiento jurídico es llamado - en la perspectiva de la racionalidad instrumental - a preparar o definir, por medio del Derecho, "las soluciones socialmente más convenientes" o "finalístico-programáticamente más oportunas o útiles e instrumentalmente adecuadas o eficaces" y no "las soluciones

Ministra Carmen Lucia, juicio de 26/09/2007. Es importante resaltar que el argumento económico y la preocupación con la maximización del bienestar general no hicieron parte del voto aportado por el Ministro Cezar Peluso, oportunidad en la que apenas fueron articulados, para el rechazo de la tesis de la ADI 3104/DF, argumentos relacionados a la teoría del Derecho, como los conceptos de derecho adquirido y posibilidad de alteración del cuadro jurídico de jubilación de los servidores públicos. Eso parece mostrar que una cosa es la fundamentación jurídica formal para la aprobación o el rechazo de determinada tesis en materia de derechos económicos, sociales y culturales; y otra es la dimensión concerniente a los efectos políticos, económicos o sociales de la decisión jurídica. Esa dimensión, orientada hacia la eficiencia económica y a la mayor utilidad posible del sistema de seguridad social comprendida en una perspectiva de maximización de las riquezas de la nación no siempre se manifiesta de manera expresa. 
axiológico-normativamente válidas y normativamente fundadas" (Neves, 1993, p. 55).

Se tiene por tanto, como fundamento la preferencia por la "pragmática utilidad (y su racional eficiencia) con relación a la axiológica justicia (y a su apelativa normatividad)". Se sigue la línea de la primacía del desempeño sobre la validez $y$, en esta lógica, "los valores se sustituyen por los fines (subjetivos) y los fundamentos (normativos) por los efectos (empíricos) y la legitimación axiológica o la "legitimación por normas" cede su lugar a la "legitimación por los efectos" (Neves, 1993, p. 55).

De esta forma, el Derecho se reduciría a una estrategia político-social funcional y finalísticamente programada. El legislador tendría en sus decisiones una táctica de realización o ejecución consecuencial, mientras que el Poder Judicial en su tarea de aplicación del Derecho - que más se aproxima del objeto central del presente trabajo -, consubstanciaría "una institución funcionalmente adecuada a esa estrategia/ táctica" (Neves, 1993, p. 55).

De este modo, la perspectiva de la realización tecnológica del Derecho, tal como pensada por Roscue Pound (1950, p. 200), el juez, considerado "un hombre que responde a diferentes estímulos sociales y personales" (Dworkin, 2002, p. 7), es conminado a actuar como agente de cambio social, de acuerdo con un "método sustancial, pragmático e instrumental” (Neves, 1993, p. 60).

La crítica que Castanheira Neves hace a la concepción funcional del Derecho toca el centro de la preocupación que abarca este estudio, cuando ve en ella la inversión del sentido de la función judicial en el cuadro del Estado de Derecho:

Si llevamos hasta sus últimas consecuencias la perspectiva en causa, lo que tendremos al final será un sistema político-jurídico en el que el derecho deja de ser tanto una normatividad de garantía como una axiología o un sistema de validez de materiales presupuestos que se sustraigan a la contingencia decisoria en una intención regulativa, y se convierte él mismo en un instrumento de todo relativizado a posteriori del propio desempeño, relativizado a sus consecuencias de momento y variables. [...] la función judicial (como paradigmática institución del Estado-de-Derecho) no pasará de una funcional longa manus de la intervención político-social o de un mero álibi legitimador. En un caso, desaparecerá el Estado de Derecho, transformando en un Estado de mera administración, y, bajo el principio, salus populis suprema lex, el derecho vuelve a ser, maquiavélico, totalitario o tecnológicamente "lo que es útil al pueblo"; en el otro caso, tendremos una real desnaturalización instrumental de la justicia" - para decirlo como ESSER - y el "fin de la actividad judicial en su auténtico sentido" (Neves, 1993, p. 61) .

La función judicial instrumental se convierte, de esta forma, en una función administrativa, con igual "intención finalístico-consecuencial y su principio estratégico--eficiente", lo que le resta sentido dentro del Estado de Derecho. Efectivamente, lo que distingue la función judicial de las demás funciones capitales del sistema político-jurídico de ese tipo de Estado es "el principio de un estatuto de independencia y como "tercero parcial", el asumir y actuar (haciendo cumplir) la "reserva de derecho" que da la dimensión de "derecho" al Estado (al sistema político-social) y a la comunidad en general" (Neves, 1993, p. 62).

Por otro lado, esa reserva y dimensión de Derecho

(...) se traducen, simultáneamente, en las garantías que formalmente el principio de la legalidad es llamado a ofrecer en los variados dominios jurídicos en los que se legitime y en la axiología específica que materialmente postula y que encuentra una expresión en los "derechos fundamentales", aun cuando en ellos no se agote (Neves, 1993, p. 62). 
Sin un sistema de validación formal y material no existe Derecho, "el derecho que el Estadode-Derecho pretende, y sin asumir ese sistema de validación para, efectivamente, imponerlo o hacerlo cumplir, de forma jurisdiccional, no tenemos la función judicial exigida por el Estadode-Derecho" (Neves, 1993, p. 62).

Por ese motivo, la racionalidad jurídica "no podrá ser una racionalidad tecnológico-estratégica, deberá ser una racionalidad orientada por una validación normativa que la fundamente, ni ésta admite ser subyugada por aquella" (Neves, 1993, p. 63).

Al final de cuentas, como bien lo expone Castanheira Neves,

[...] la aceptación metodológica de la perspectiva fundamentalmente finalísticoconsecuencial, en la que los efectos serían los criterios (cfr. H. ROTLEUTHNER, Rechtssystem y Rechtsdogmatik, cit., p. 31 ss.) o que aceptaría como ápice decisivo la "aplicación del derecho" orientada por los "efectos" (cfr. H. ROTLEUTHNER, Rechtssystem y Rechtssoziologie, p. 210 ss.), convertiría, consecuentemente, el pensamiento jurídico en una "ingeniería social" (v. supra) y la ciencia jurídica en una "ciencia social" (ciencia político-social), también en el sentido estricto de la expresión (cfr. H. ROTLEUTHNER, Rechtswissenschaft als Sozialwissenschaft, p. 117; Id., "Zur Methode einer folgenorientierter Rechtsanwendung", in A.R.S.P., Beiheft n. folge, p. 13 y 97 ss.; Método Jurídico, p. 257 y 275 ss.) (Neves, 1993, p. 196).

Medir las consecuencias económicas es sumarle importancia a la eficiencia, lo que, en lo que atañe a los derechos económicos, sociales y culturales, se traduce en a) priorizar la maximización de las riquezas estatales (depósito de expectativas colectivas) en detrimento del individuo y sus necesidades, y b) olvidarse de los importantes fundamentos éticos que permean singularmente los derechos humanos y justifican el correlativo sistema de protección.

Efectivamente, la tendencia de preponderancia de las consecuencias sistémicas de una decisión judicial - asimilándolas a los efectos de una regla en abstracto - y la presuposición de que ellas pueden promover/realizar o amenazar/violar determinado bien público ("histórico-culturalmente 'sentido' como 'adquisición' común”), autoriza la clasificación de esas consecuencias como positivas o negativas.

En el conjunto de bienes públicos que pueden ser afectados por las consecuencias de las decisiones se encuentran la previsibilidad de la decisión, el pluralismo y el liberalismo políticos, la preservación de los mercados competitivos, la separación de los poderes.

En un edificio que culmina en la trinidad ejemplar de la "estabilidad política", "prosperidad económica" y "felicidad individual" - y en la concertaciónconcretización de opciones (si no de argumentos) liberales, pragmáticos y económicos que la hacen reflexivamente plausible (Neves, 1993, p. 219).

La ideología de la "permanencia del estado de emergencia económica" caracteriza cada vez de modo más incontrovertible la eficiencia económica de los sistemas de protección social como bien público de destacada posición, el verdadero principio que se encuentra subyacente a la política de reafirmación del equilibrio fiscal.

Teniendo como objetivo el establecimiento de instituciones jurídicas estables y capaces de ofrecer los mejores incentivos para el desarrollo socioeconómico, la relevancia de las consideraciones de carácter económico de una decisión judicial parece ser incuestionable, principalmente después de las crisis económicas globales y la difusión de la administración de perfil liberal - modelo de gestión tomado de las empresas privadas (que se encuentran en un mercado 
competitivo) - orientado a la reducción de costos y la eficiencia ${ }^{26}$.

De hecho, mientras menos intervención estatal - en la educación, seguridad social o infraestructura, por ejemplo -, mayor la economía de recursos públicos y las posibilidades de alcanzar el superávit presupuestario, mucho más propio de la atmósfera de rigor fiscal, presupuesto considerado necesario para el adecuado funcionamiento del mercado globalizado.

Se encuentra ahí la meta final del raciocinio económicamente orientado o de la preocupación con el impacto económico de las decisiones: la supremacía de la eficiencia sobre el derecho de protección humana contra la necesidad, con la subyacente noción de que la satisfacción de un derecho social puede implicar el sacrificio de toda la colectividad, por la variación negativa del poder adquisitivo de la moneda en razón del déficit público, debido a los graves daños causados a la economía en general.

Desde esta perspectiva, los gastos sociales decurrentes del ejercicio de los derechos económicos, sociales y culturales serían, finalmente, perjudiciales al desarrollo de la vida económica y social como un todo, pues presuponen reservas de costeo que implican el aumento de costo de las empresas, con repercusión final en los productos y servicios que se ofrece al mercado de consumo global.

Aceptar esta tesis implica aceptar la consideración excluyente de que el ser humano no representa

26 Partiéndose de la suposición económica de que los recursos son escasos y de que los agentes son racionales y maximizadores de utilidad, cada individuo buscará dar a sus recursos el mejor destino buscando maximizar su bienestar. Sigue el pensamiento: Si los recursos son escasos, la escasez alcanza a todos indiscriminadamente, de tal forma que, en tesis, sus potenciales beneficiarios pagan el precio de la ineficiencia de destino de las entidades administradoras. De esa forma, la restricción de acceso a algunas personas a esos derechos disminuye el costo social, contribuyendo para la eficiencia del sistema, maximizándole la riqueza y disminuyendo el grado de escasez que lo afectaba. un valor en sí mismo, sino un valor relativo a la funcionalidad del sistema económico (Camargo, 2008, p. 108).

Rescatemos en este punto, la lapidaria objeción de Luhmann a las decisiones judiciales orientadas exclusivamente a los resultados:

Si se quiere hacer uso de las consecuencias jurídicas como puntos de orientación o incluso de justificación [...] es necesario usar anteojeras que impidan ver todas las consecuencias, las consecuencias de las consecuencias, los eventuales efectoslímite de las consecuencias agregadas de una multiplicidad de decisiones (citado por Larenz, 1997, p. 320).

Cuando presume que la consecuencia económica de una decisión denegatoria de protección social será la economía de recursos del presupuesto ${ }^{27}$, el juez le da la espalda a las consecuencias sociales de la tragedia moral de una necesidad humana vital que fue expuesta y que no fue sanada $^{28}$. En la otra cara de la moneda, para la persona que está recibiendo el juzgamiento, tales presunciones se traducen en potencial inmediato de exclusión social y marginalización. Esos efectos, imaginables en el contexto de una creciente desigualdad social, pueden dificultar aún

27 Con supuestas consecuencias sociales deseables por toda colectividad, tales como : (1) el fortalecimiento financiero de las instituciones públicas responsables por esos servicios sociales; (2) el destino más eficaz, en el presente o en el futuro, de los recursos salvaguardados por la decisión denegatoria, o sea, empleo de recursos en hipótesis que más fuertemente o indudablemente justifiquen la realización de los derechos sociales.

28 Si la persona no dispone de recursos materiales (propiedades, cuenta de ahorro individual etc.) para proseguir en su vida con autonomía y dignidad, la llaga persistirá y la ruina de aquel a quien le fue negada la dignidad y se encuentra a La deriva contribuye para un cuadro de deterioración social. Tal necesidad impulsará a la persona carente a buscar, debido a la necesidad de sobrevivencia y siempre en condición de inseguridad e inferioridad, acciones de solidaridad en la informalidad de las relaciones que se dan en el seno de la sociedad. 
más la cohesión social y amenazar la seguridad de todos, la seguridad social ${ }^{29}$.

Al expresar que debemos tomar en serio los derechos, Dworkin tiene como objetivo, precisamente, demostrar que las políticas no deben considerarse justificadas por el hecho de producir más beneficios que daños, aunque se restrinjan los derechos de los ciudadanos ${ }^{30}$.

Frente a las consideraciones expuestas hasta este punto, es imperativo indagar si después de todo, existe algún espacio para el consecuencialismo en la aplicación judicial de los derechos económicos, sociales y culturales. A ese tema se dedica la sección final del presente trabajo.

\section{EL CONSECUENCIALISMO POSIBLE (Y NECESARIO) EN LA APLICACIÓN DE LOS DESC}

El presente trabajo critica la ética consecuencialista-utilitarista en la aplicación judicial de los derechos económicos sociales y culturales.

Pero eso no significa la adopción de un modelo formal de lógica deducción normativa

29 No obstante, en un sentido utilitarista la comunidad puede considerarse mejor como un todo "porque o nível médio ou coletivo do bem-estar comunitário aumentou [pela eficiência supostamente alcançada com decisões denegatórias de direitos sociais], apesar de o bem-estar de alguns indivíduos [presumivelmente destituídos de recursos para subsistência e desenvolvimento] ter diminuído" (Dworkin, 2002, p. 358).

30 No se puede afirmar, entonces, "que o governo está justificado ao desconsiderar um direito com base em razões de pouco peso, que seriam suficientes se nenhum direito desse tipo existisse. Ele não pode afirmar que o governo está autorizado a agir baseandose simplesmente no juízo de que seu ato provavelmente produzirá, no cômputo geral, um benefício para a comunidade. Essa suposição tornaria despropositada sua pretensão a um direito, e revelaria que ele usa a palavra "direito" em outro sentido que não o forte, necessário para conferir à sua alegação a importância política que normalmente se imagina que tenha. Direito "em sentido forte" corresponderia àquele que é protegido contra interferência estatal sem razões especiais que a justifiquem" (Dworkin, 2002, p. 294). como alternativa a la perspectiva finalísticoconsecuencial, ya que tal modelo no significaría sino "la definición sistemático-estructural y metódica del pensamiento jurídico, según el esquema lógico-subsuntivo de la determinación del derecho", revelándose además, ajena a una "intencionalidad normativo-material y de justedad problemático-concreta" (Neves, 1993, pp. 196-197).

Se busca, principalmente, la reafirmación de la racionalidad material en el discurso jurídico de los derechos humanos como medio de superación del eje conceptualista-utilitarista en la aplicación judicial de los derechos económicos, sociales y culturales.

Se hace necesario, entonces, asumir que el Derecho es una validación normativa (con posible mediación normativa y dogmática) que se desenvuelve en el problema concreto, de tal modo que el pensamiento jurídico se perfecciona como pensamiento judicativo-decisorio.

En esta línea de pensamiento, el objeto principal de reflexión es el problema mostrado por el caso, mientras que los principios axiológico-normativos guardan la preponderancia en la fundamentación de la solución. Se trata de una posición "que comprende el derecho como validación (axiológica-normativa) de realización problemática y en la que el pensamiento jurídico está llamado a resolver problemas prácticos con actitud prácticojurisprudencial" (Neves, 1993, p. 71) ${ }^{31}$.

31 Cabe perfectamente la observación: "Decerto que as perspectivas teorético-normativas, o jusnaturalismo $e$ o positivismo jurídico, na 'verdade' que se propunham não deixavam de ver a expressão de una validade (una validade onto-axiológica ou antropológico-axiológica no jusnaturalismo, e a validade de una legalidade, no positivismo jurídico), simplesmente, enquanto a visavam como objecto, não só apagavam nessa intencionalidade teorética o seu verdadeiro sentido normativo como, e já por isso, não compreendiam que una validade normativa enquanto tal convoca sua histórica realização concreta e que esta não é cumprida apenas pela força do enunciado e determinação gerais da sua normatividade, antes exige sempre una mediação judicativa na solução dos problemas que a solicitam" (Neves, 1993, p. 71). 
La decisión judicial debe manifestarse en un discurso argumentativo, propio del dominio de la racionalidad práctica de índole material racionalidad práctica axiológica (Wertrationalität), perspectiva que se ajustaría a la concepción metodológica jurisprudencial, en la clasificación de Castanheira Neves.

Es indispensable que se cumplan, por medio da aplicación del Derecho, los postulados materiales que justifican o exigen la organización de un sistema de protección social que garantice la realización de los derechos económicos, sociales y culturales.

La reafirmación de la racionalidad material en el discurso jurídico de los derechos humanos presupone dos pensamientos fundamentales y recíprocamente complementarios.

Por un lado, emerge la idea de que el Derecho se aplica/realiza en - y de acuerdo con - el caso, para hacer llegar la justicia al problema concreto. Por otra parte, se afirma que también es fundamental para la aplicación judicial del Derecho que se consideren los resultados reales o externos de la decisión, pero solamente aquellos que confirman los fundamentos morales que justifican y apoyan el sistema jurídico de protección social ${ }^{32}$.

Es falsa la suposición de que la alternativa entre formalismo y consecuencialismo se resuelve sólo por medio de una disyunción excluyente (MacCormick, 1983). El motivo es que la negación de sumisión de la racionalidad metodológicojurídica a un programa instrumental no significa aceptar la reducción de esa racionalidad al modelo que define el pensamiento jurídico según el esquema lógico-subsuntivo de la determinación del Derecho (Neves, 1993, p. 196).

32 El pensamiento consecuencialista complementa al primero en la medida en que la idea de justicia para el caso no prescinde de los efectos reales sentidos por las personas debido a la decisión jurídica. Por otro lado, el argumento para los efectos está, en estos términos, vinculado a la axiología normativa de La que parte el proceso de decisión para el caso concreto.
Lo que demuestra la justicia de la decisión para el caso es la proporción de los términos en que se soluciona el problema jurídico en relación con los resultados finales provocados por la realización del Derecho en la especie. Se pretende evaluar la justicia de la ponderación entre los criterios de la norma abstracta (intencionalidad normativa) y las exigencias de justicia del caso concreto que reclama la adjudicación judicial (realidad problemático-decidenda) ${ }^{33}$. No existiría realmente una conformación equitativa de la norma para el problema concreto si no se evaluaran las consecuencias futuras de la decisión, que consubstancian finalmente, su verdadero significado sobre la vida de los individuos y de la comunidad ${ }^{34}$.

En la obra que plasma las tesis fundamentales de su teoría de la argumentación jurídica, Legal reasoning and legal theory, publicada en 1978, Neil MacCormick afirma que en el ámbito de la teoría del derecho, todos parecen estar seguros de que alguna especie de consecuencialismo tiene alguna participación en la argumentación, pero es mucho menos claro saber qué especie y qué parte $e^{35}$. A continuación, las preguntas

33 Se debe recordar que la adjudicación jurídica debe considerarse como la decisión jurídica final que aplica el Derecho (la última aplicación jurídica del Derecho), concluyendo el caso en cualquier nivel de jerarquía de los organismos jurisdiccionales.

34 De acuerdo con la conocida dicotomía elaborada por Max Weber entre la "ética de la convicción" (Gesinnungsethik), de carácter deontológico, y la "ética de la responsabilidad" (Verantwortungsthik), de índole teleológica (Weber, 1993. p. 113), se parte aquí de la concepción de que es fundamental también para a la aplicación judicial de los derechos económicos, sociales y culturales que se tome en cuenta el resultado de la decisión.

35 John Dewey, uno de los más importantes filósofos americanos de la primera mitad del siglo XX, sustentó de modo original que el pensamiento jurídico sigue una "lógica de búsqueda y descubrimiento", de índole instrumental, de acuerdo con la cual las reglas jurídicas y principios son "hipóteses de trabalho, precisando ser constantemente testadas em conformidade com o seu desempenho na aplicação a situações concretas'. Essa lógica jurídica instrumental 'é uma lógica relativa a conseqüencias preferencialmente a antecedentes, uma lógica de predição de probabilidades preferencialmente a uma de dedução de certezas". (citado en Golding, 
de MacCormick: ¿Existe algún tipo de consecuencia particularmente relevante para las decisiones judiciales? ¿Por qué estándares de evaluación las consecuencias deben analizarse y juzgarse como mejores o peores, aceptables o inaceptables? (MacCormick, 1983, p. 241) En otras palabras, "¿qué 'responsabilidad' debe asumir específicamente el juzgadordecisor, qué 'consecuencias' deberá considerar concretamente?" (Neves, 1993, p. 203).

Partiendo de la diferenciación hartiana entre "clear cases" y "hard cases", MacCormick reconoce que en los primeros, el juez comúnmente tiene como punto de referencia las reglas de derecho que no son ambiguas, valiéndose de una justificación deductiva de primer orden que puede ser una justificación suficiente (MacCormick, 2006, p. 24) ${ }^{36}$.

Pero, en los casos difíciles las reglas jurídicas exigen interpretación y justificación más elevadas. En tales casos, la justificación deductiva sólo es posible después de resolver el problema interpretativo, lo que hace necesaria una justificación de segundo orden que muestra que la interpretación es necesaria. La justificación de segundo orden contiene dos elementos argumentativos: el primero, pretende contribuir a la decisión al indicar que la regla interpretada de una determinada manera muestra consecuencias aceptables (argumentación consecuencialista); el segundo, pretende contribuir a la decisión, al demostrar que la regla interpretada de tal modo está en concordancia con el sistema jurídico

2010. p. 144). Junto con esa lógica de búsqueda y descubrimiento, existiría la "lógica de la exposición", de índole formal, "que está em jogo quando juízes declaram aos outros as razões justificantes das conclusões a que eles podem ter chagado (sic) de outra maneira. Fundamentos são oferecidos de maneira que a decisão não apareça como uma sentença arbitrária, e para que possa indicar uma regra a ser usada em casos similares no futuro" (en Golding, 2010, p. 144).

36 Sin embargo, como observa el mismo autor: "Não se pode dizer se o caso com que nos deparamos é fácil ou difícil enquanto não tivermos refletido sobre os princípios, bem como sobre a norma ou normas aplicáveis à primeira vista" (2006, p. 302). existente (argumentación por la coherencia o cohesión) (MacCormick, 2006, p. 137).

En la medida en que las decisiones judiciales tratan sobre el mundo real, en el contexto de todo el cuerpo del sistema de derecho normativo, también "deben tener sentido en el mundo y también tener sentido en el contexto del sistema jurídico" (MacCormick, 2006, p. 131) ${ }^{37}$.

La justificación de segundo orden envuelve la verificación de posibles deliberaciones o alternativas recíprocamente opuestas, por medio de la comparación de una con la otra, rechazando aquellas que no satisfagan las exigencias de tener sentido en el mundo y tener sentido en el contexto del sistema normativo.

El primer elemento esencial de la justificación de segundo orden es la argumentación de naturaleza consecuencialista, que corresponde a la exigencia de que la decisión debe tener sentido en el mundo. Ésta surge del análisis de los efectos de las alternativas decisorias y aun hasta el punto de "examinar los tipos de decisiones que tendrían que tomarse en otros casos hipotéticos que podrían ocurrir y que se encuadrarían en los términos de la deliberación" (MacCormick, 2006, p. 133). También presenta un "carácter intrínsecamente valorativo", ya que indaga "sobre la aceptabilidad o inaceptabilidad de esas consecuencias", revelándose, justamente por esa razón, por lo menos en parte, subjetiva (MacCormick, 2006, pp. 133-134).

37 En un importante texto en el que sustenta la indispensabilidad del derecho a la Seguridad Social, Marcus Orione expresa esencialmente esa conocida idea de MacCormick: "A teoria do direito constitucional, já se reconhece, tem um pouco de ciência da realidade e outra tanto de ciência normativa. Não se pode, no entanto, deixar que os elementos de ciência da realidade tomem conta por completo da interpretação constitucional, sob pena de o aspecto normativo ser relegado a segundo plano. Da mesma forma, para que a Constituição tenha força normativa não basta una interpretação meramente literal. Na realidade, já dizia Konrad Hesse, a força normativa da Constituição decorre da confluência dos dois fatores (realidade/ norma) que a informam”. (Correia, 2004, p. 38). 
El segundo elemento fundamental de la justificación de segundo orden es el que trata sobre la exigencia de que las deliberaciones deben tener sentido en el sistema jurídico como cuerpo coheso y coherente de normas "cuja observancia garantiza ciertos objetivos valorizados que pueden buscarse en conjunto de modo integral" (MacCormick, 2006, pp. 135).

Dada la exigencia de cohesión, por más deseable que sea una deliberación a partir de fundamentos consecuencialistas "no puede ser adoptada si está en contradicción con alguna norma válida y de carácter obligatorio del sistema" ${ }^{38}$. El rechazo de la deliberación sería impuesta en tales condiciones, debido a "su conflicto insoluble con (la contradicción de) normas válidas y establecidas" (MacCormick, 2006, pp. 138).

Por su parte, la coherencia requiere la consonancia de la deliberación con un principio racional que pueda explicar o justificar el tratamiento sugerido. La elección entre los modelos o estándares posibles debe ofrecer una solución coherente con el sistema jurídico, traduciendo "valores inteligibles y mutuamente compatibles". La nueva deliberación debe ser coherente con el sistema jurídico, haciendo referencia a sus diversas normas, frente a los casos concretos, como manifestación de los principios más generales: "la exigencia de coherencia llega solamente hasta donde nuevas deliberaciones manifiestas puedan incorporarse al ámbito del cuerpo existente del principio jurídico general" (MacCormick, 2006, pp. 136).

En la medida en que la prueba de la coherencia envuelve reflexiones sobre los valores del sistema, y una vez que la argumentación consecuencialista es intrínsecamente valorativa, las dos argumentaciones interactúan y se sobreponen. En otras palabras, "existe una interrelación necesaria entre los argumentos consecuencialistas y el tipo de

38 Se debe hacer la salvedad de que MacCormick denomina "estratagema para la conciliación" (entre las consecuencias y el sistema), o sea, la posibilidad de interpretarse una ley ostensivamente conflictante de tal forma que se evite esa contradicción. argumento dictado con exigencia de "coherencia"" (MacCormick, 2006, pp. 142).

Con relación a la aceptabilidad de las consecuencias, el juez debe orientarse de acuerdo con los fundamentos morales y los principios fundamentales del sistema jurídico, sin que exista ninguna razón para que la valoración de las consecuencias se dé "en los términos de una única escala, como por ejemplo, la escala benthamita de agregados supuestamente mensurables de placeres y dolores" (MacCormick, 2006, pp. 134).

Tal pensamiento se alinea con la idea aquí sustentada de que el ejercicio del Derecho debe darse a partir de una racionalidad preponderantemente comprometida con los fundamentos axiológico-normativos de un determinado sistema jurídico. Eso significa, por un lado, denegar la adjudicación judicial formalista, analizada a través de un raciocinio de lógica formal correspondiente a una racionalidad cerrada a valores. Por otro lado, el empleo de la racionalidad material hace resistencia a la instrumentalización del Derecho para el logro de objetivos sociales, políticos y económicos convenientes en determinado momento histórico, lo cual es propio del utilitarismo social. Eso se debe a que la racionalidad instrumental, orientando las acciones según las metas u objetivos comunitarios - aun cuando considerados expresa o implícitamente por el Derecho vigente - también está cerrada a valores.

Libre de la perspectiva formal, la aplicación judicial del Derecho se orienta a través de los resultados que reafirman el conjunto axiológiconormativo de un determinado derecho vigente. Se debe buscar entonces, según la ética de la responsabilidad, las consecuencias externas de la decisión que refuercen los principios que sustentan al sistema jurídico. Específicamente, con relación a la problemática de los derechos económicos, sociales y culturales, es menester investigar, en la solución jurídica del caso concreto, las consecuencias que respetan o enaltecen el conjunto de (normas-fundamentos morales-principios) que fundamentan o justifican la existencia de un sistema de protección social. 
A estas alturas, es importante reafirmar la distinción teórico-política entre los estándares normativos que no se confunden con las reglas (principio y política) para, también a partir de la "tesis de los derechos" de Dworkin, encontrar en la asociación entre argumentos de principio y argumentos consecuencialistas un paso fundamental para la proposición del presente trabajo ${ }^{39}$.

Con relación a los fundamentos esenciales de la justificación política, "los argumentos de política justifican una decisión política, al mostrar que la decisión fomenta o protege algún objetivo colectivo de la comunidad como un todo", mientras que "Los argumentos de principio justifican una decisión política, al mostrar que la decisión respeta o garantiza un derecho de un individuo o de un grupo" (Dworkin, 2002, p. 129) ${ }^{40}$.

En los asíllamados casos difíciles, cuando la tarea jurídica no puede limitarse a la aplicación de los términos de una regla de validez incuestionable, aparentemente la decisión puede generarse tanto por argumentos de principios como por argumentos de política (policy) (Dworkin, 2002, p. 131). Según la "tesis de los derechos", en su aspecto normativo, los jueces deben usar

39 Dice Dworkin: "Denomino "política" aquele tipo de padrão que estabelece um objetivo a ser alcançado, em geral una melhoria em algum aspecto econômico, político ou social da comunidade (ainda certos objetivos sejam negativos pelo fato de estipularem que algum estado atual deve ser protegido contra mudanças adversas). Denomino "principio" um padrão que deve ser observado, não porque vá promover ou assegurar una situação econômica, política ou social considerada desejável, mas porque é una exigência de justiça ou eqüidade ou alguma outra dimensão da moralidade" (2002, p. 36). O, como en otro lugar señala este mismo autor: "Os princípios são proposições que descrevem direitos; as políticas são proposições que descrevem objetivos" (2002, p. 141).

40 O en otra versión: "Os argumentos de principio tentam justificar una decisão política que beneficia alguma pessoa ou algum grupo mostrando que eles têm direito ao benefício. Os argumentos de política tentam justificar una decisão mostrando que, apesar do fato de que os beneficiados não têm direito ao benefício, sua concessão favorecerá um objetivo coletivo da comunidade política" (Dworkin, 2002, p. 452). argumentos de principio y evitar argumentos de política (Dworkin, 2002, p. 452).

No sería apropiado al Derecho la imposición de un nuevo deber, creado después de un hecho determinado, sólo para mejorar la eficiencia económica global (Dworkin, 2002, p. 151). De igual forma, no se debe aceptar el no reconocimiento de un determinado derecho - en tesis, existente en el sistema jurídico - ponderando su existencia frente a los intereses de una determinada política económica, como el desarrollo y fortalecimiento de una economía capitalista ${ }^{41}$.

El modelo decisorio inspirado en la ética utilitarista (argumento de política) no satisface la exigencia de aplicación judicial del Derecho como solución de un problema concreto de acuerdo con una validación normativa vinculante - principalmente, cuando se trata de la satisfacción de derechos sociales de una minoría en época de crisis económica. Lo decisivo, para la aplicación del Derecho, son los fundamentos normativos relacionados con el caso concreto, y no los efectos empíricos o el impacto de determinado derecho sobre las metas colectivas.

En la medida en que "Los argumentos de principio son argumentos destinados a determinar un derecho individual" y "los argumentos de política son destinados a determinar un objetivo colectivo" (Dworkin, 2002, p. 141), la colonización de los

41 Por otra parte, el argumento de política no se somete de forma significativa a la "consistencia articulada", así entendida la coherencia necesaria entre los fundamentos adoptados por una determinada decisión política y hipotéticas decisiones futuras, de forma que estas sean comprendidas como una sustentación de la misma política. Por su lado, un argumento de principio puede ofrecer una justificación para una decisión particular "solamente si es posible mostrar que el principio citado es compatible con decisiones anteriores que no fueron rehechas, y con decisiones que la institución está preparada para tomar en circunstancias hipotéticas" (Dworkin, 2002, p 138). Las decisiones, así, "parecen correctas aisladamente", pero "no pueden hacer parte de una teoría que abarque los principios y de las políticas generales que sea compatible con otras decisiones igualmente consideradas correctas" (Dworkin, 2002,p. 137). 
primeros por los últimos, tal como sucede en la visión utilitarista, implica la subordinación o instrumentalización de los derechos a los objetivos.

Si lo que está en juego es el derecho de un individuo o grupo a la protección social - y no la conveniencia de reafirmación de un determinado objetivo comunitario o de una determinada política económica -, el raciocinio jurídico debe orientarse por los principios ético-jurídicos que fundamentan o justifican la existencia de un sistema de protección social.

Es importante reconocer, junto con Dworkin y MacCormick, que la argumentación con principios no significa necesariamente una justificación no consecuencialista. De hecho, nada impide que consideraciones consecuencialistas se hagan a partir de un argumento de principio (Dworkin, 2002, pp. 454-455). Lo decisivo es saber si, de acuerdo con el sistema normativo considerado a partir de sus principios e igualmente del cálculo de las consecuencias de la decisión, el derecho existe.

El reconocimiento jurídico en materia de derechos económicos, sociales y culturales no se debe hacer por la vía del consecuencialismo económico, que implica la adopción de argumentos de política propios de una racionalidad instrumental y, por lo tanto, escapa de la pauta axiológica que sostiene nuestro sistema jurídico de protección social.

El fundamento de la decisión judicial frente a los derechos económicos, sociales y culturales debe tener como base la argumentación a partir de principios, esos estándares normativos que, consubstanciando la exigencia de justicia o equidad u otra dimensión de la moral, justifican o reclaman la existencia de esos derechos ${ }^{42}$.

42 Desde la misma perspectiva, pero formulándose por medio una proposición negativa: el juez no debe orientarse a partir de un raciocinio judicial instrumental que, expresa o implícitamente, busca justificar la decisión sobre los derechos sociales, económicos y culturales en aquello que sirve para fomentar un objetivo - económico, político o social de la comunidad - a ser alcanzado (argumento de política).
Además, es necesario dirigir la atención hacia los efectos externos de la decisión en aquello que afecta esas normas y exigencias de justicia que se encuentran a subyacentes a ella, procurando en el caso concreto, la solución equitativa que reafirme el conjunto axiológico-normativo que justifica la individualización del objetivo político de protección social.

Sin limitarse a la racionalidad decisoria estrictamente apriorística y axiomático-deductiva - "sin consideración pragmática de las circunstancias concretas de la situación problemático-decisoria" - el juez debe navegar "en una fundamentación normativa material que garantice la consonancia práctica entre los fundamentos invocados y el contenido normativo-concreto de su realización", fundamentación ésta que es "situacional-pragmáticamente referida y se asume constitutiva y concretamente responsable" (Dworkin, 2002, pp. 203-204).

El raciocinio jurídico debe considerar el problema concreto sobre el que va a decidir - incluyendo las consecuencias reales de la decisión sobre los agentes involucrados - orientándose por los fundamentos axiológico-normativos de los derechos económicos, sociales y culturales y por las consecuencias que refuerzan esos fundamentos.

De esta forma, queda demostrada la única consideración de los efectos de la decisión aceptable por el pensamiento metodológico-jurídico, en la medida en que reconoce el derecho como una ética de responsabilidad, aunque actuando en la inmanencia intencional de la juridicidad (de la axiológica normatividad jurídica) (Dworkin, 2002, pp. 204-205).

Es justamente ese el espacio para el consecuencialismo jurídico y ese sustrato teórico sirve como apoyo a la idea de que el juez es responsable por los - y debe considerar - los efectos externos que provocan sus decisiones.

Sólo resta relacionar la argumentación metodológica aquí sustentada con los problemas jurídicos teniendo como referencia los derechos económicos, sociales y culturales. Eso implica 
investigar los principios (y no las metas) que justifican y constituyen la estructura del sistema jurídico de protección social. Serán ellos los que, finalmente, arrojarán luces sobre la naturaleza de las consecuencias que deben ser sopesadas y juzgadas como buenas o malas, aceptables o inaceptables.

Definir las consecuencias que pueden y deben ser tomadas en consideración en la aplicación judicial de los derechos económicos, sociales y culturales presupone el análisis de la pauta moral que consubstancia los principios que fundamentan un sistema de protección social.

Efectivamente, a partir de los fundamentos morales que justifican o reclaman la existencia de un sistema de protección social se alcanzan los principios jurídicos que aglutinan tal pauta axiológica y la revisten de normatividad jurídica.

Por ser una mediación entre la pretensión de la norma y la realidad del caso concreto, la aplicación judicial de los derechos económicos, sociales y culturales debe dirigirse al reconocimiento y promoción de una consecuencia principal: la protección de una persona que se presume se encuentra en una contingencia de necesidad económica, social o cultural. En otras palabras, el factor más importante de la realidad es la vida humana y sus posibilidades de preservación condigna frente al resultado jurídico de la decisión. Esa consecuencia está directamente relacionada con el fundamento axiológico-normativo del sistema jurídico de esos derechos humanos, que es precisamente la protección contra la necesidad y la garantía de los medios para el desarrollo ${ }^{43}$.

El argumento de la protección contra la necesidad humana y para su desarrollo e integración social, justificador de los principios que fundamentan los derechos económicos, sociales y culturales,

43 En este punto es de crucial importancia rescatar lo que fue articulado en la primera parte de este trabajo, referente a la fundamentación moral de los derechos económicos, sociales y culturales. consubstancia legítima adopción de consideraciones consecuencialistas en materia social.

El consecuencialismo jurídico en el tema de los derechos sociales, económicos y culturales es aceptable sólo en esos términos. Y en esos términos, es momento integrante indispensable de la constitución equitativa de la norma en el caso concreto.

\section{CONSIDERACIONES FINALES}

El hecho de que la ética consecuencialista se sujete a la fuerza normativa de los derechos económicos, sociales y culturales, es probablemente la idea central de la propuesta que desarrolla el presente estudio. El modo contingente de lo que es útil o conveniente en determinado tiempo y lugar, de acuerdo con la percepción política de un determinado momento histórico, se contrapone a la eficacia axiológico-normativa de los derechos humanos y fundamentales (eficacia normativa de la Constitución, en último análisis, sus principios más generales y sus objetivos más fundamentales).

Por medio de la labor hermenéutica, el juez no sólo dicta la Constitución, como también cuánto vale y para qué sirve esa Constitución.

El consecuencialismo utilitarista hospeda la tesis de que el juez, al aplicar el Derecho, debe ofrecer una solución cuyo resultado traduzca un estado más ventajoso en términos de maximización de preferencias, intereses o prosperidad de la comunidad. En una situación de contingencia económica crítica, la solución utilitarista se muestra como una salida conveniente. Importantes decisiones judiciales pueden pensarse en términos más estratégicos que jurídicos. Dichas decisiones pueden concebirse como un medio para alcanzar el objetivo considerado socialmente útil.

Esa racionalidad instrumental en la aplicación judicial de los derechos económicos, sociales y culturales no puede ser aplaudida por la metodología jurídica ni en momentos de crisis. Entre otras cosas, era algo parecido lo que había 
considerado Konrad Hesse cuando expresó la célebre noción de que no es en tiempos tranquilos y felices que la Constitución normativa se ve supeditada a su propia fuerza, sino en las situaciones de emergencia, en los tiempos de necesidad (Hesse, 1991, p. 25).

\section{REFERENCIAS}

Abramovich, V. \& Courtis, C. (2002). Los derechos sociales como derechos exigibles. Madrid: Trotta.

Alexy, R. (2005). Teoria da argumentação jurídica: A teoria do discurso racional como teoria da justificação jurídica. São Paulo: Landy Editora.

Bercovicci, G. (2004). Constituição e estado de exceção permanente. Atualidade de Weimar. Rio de Janeiro: Azougue.

Bobbio, N. (1995). Positivismo jurídico: lições de filosofia do direito. São Paulo: Ícone.

Camargo, R. A. L. (2008). "Custos dos direitos" e reforma do Estado. Porto Alegre: Sergio Antonio Fabris.

Coelho, L. F. (2008). A fundamentação dos direitos humanos. En Cambi, E. et al. (Organizadores). Direitos fundamentais revisitados. (39-88). Curitiba: Juruá.

Correia, M. O. G. (2004). Os direitos sociais enquanto direitos fundamentais. En Correia, É. P. B. (Coordenadores). Direito Previdenciário e Constituição. (25-43). São Paulo: LTr.

Cortés, L. E. (2010). Globalización, ética y De-rechos Humanos. Propuesta para afrontarlos desde la Universidad. En Hernández, C. A. et al. Globalización y Derecho, Bogotá: Universidad Libre.

Cruz, P. M. (2005). Fundamentos Históricos, Políticos e Jurídicos da Seguridade Social. En Rocha, D. M. \& Savaris, J. A. Curso de Especialização em Direito Previdenciário, 1. (p. 11-92). Curitiba: Juruá Editora.

Dworkin, R. (2002). Levando os direitos a sério. São Paulo: Martins Fontes.
Esping-Andersen, G. (1999). Social Foundations of Postindustrial Economies. Oxford: Oxford University Press.

Esping-Andersen, G. (1996). After de Golden Age? Welfare State Dilemmas in a Global Economy. En Welfare States in: Transition. National Adaptations in a Global Economies, London: Sage Publications.

Gadamer, H. G. (2003). Verdade e Método I: Traços fundamentais de uma hermenêutica filosófica. Petrópolis: Vozes.

Golding, M. (2010). Filosofia e teoria do direito. Tradução de Ari Marcelo Solon. Porto Alegre: Sergio Antonio Fabris.

Hart, H. L. A. (1979). Between utility and rights. En Ryan, A. (ed.). The idea offreedom. (p. 77-98).

Heck, P. (1999). El problema de la creación del derecho. Granada: Editorial Ariel.

Hesse, K. (1991). A força normativa da Constituição. Porto Alegre: Sergio Antonio Fabris.

Hoffe, O. (2003). O que é Justiça? Porto Alegre: EDIPUCRS.

Holmes, S\&Sunstein, C. R. (2000). The Cost of Rights: Why Liberty Depends on Taxes. New York: Norton.

Iannuccilli, L. Problemi dell'omissione legislativa nella giurisprudenza costituzionalle, Parte I-Profili storici e teorici. p. 2-25 (p. 11). Disponível em: $<$ http://www.cortecostituzionale.it/documenti/ convegniseminari/STU199_Omissione_legislatore.pdf>. Acesso em: 26 jan 2012.

Ihering, R. v. (2002). A finalidade do Direito. Campinas: Bookseller.

Kant, I. (1980). Os Pensadores - Kant (II). Fundamentos da metafísica dos costumes. (p. 103-162). São Paulo: Abril Cultural.

Larenz, K. (1997). Metodologia da ciência do direito. Lisboa: Fundação Calouste Gulbenkian.

Lopes, J. R. L. (2008). Em torno da reserva do possível. En Sarlet, I. W. \& Timm, L. B. (Orgs.). Direitos fundamentais: orçamento $e$ 
reserva do possível. (p. 173-193). Porto Alegre: Livraria do Advogado.

MacCormick, N. (2006). Argumentação jurídica e teoria do direito, São Paulo: Martins Fontes.

MacCormick, N. (Mayo de 1983). On legal decisions and their consequences. New York University Law Review, 58, 2, 239-258.

Morais, J. L. B. (2006). Crises do Estado, democracia política e possibilidades de consolidação da proposta constitucional. En Canotilho, J. J. \& Streck, L. L. Boletim da Faculdade de Direito Stvdia Ivridica, 89 - Entre discursos e culturas jurídicas. Coimbra: Universidade de Coimbra.

Neves, A. C. (1993). Metodologia jurídica: problemas fundamentais. Coimbra: Universidade de Coimbra.

Ortega, M. (1998). La racionalidad jurídica. Madrid: Tecnos.

Perelman, C. (2004). Lógica jurídica. São Paulo: Martins Fontes.

Pierson, P. (2001). The New Politics of the Welfare State. Oxford: Oxford University Press.

Pierson, P. (1994). Dismantling the Welfare State? Reagan, Thatcher, and the Politics of Retrenchment. Cambridge: Cambridge University Press.

Polanyi, K. (2000). A grande transformação: as origens da nossa época. Rio de Janeiro: Elsevier.

Pound, R. (1950). Las grandes tendencias del pensamiento jurídico. Barcelona: Ediciones Ariel.

Posner, R. (1983). The economics of justice. Harvard: Cambridge University Press.

Rawls, J. (1971). A theorie of justice. Cambridge (Mass.): Harvard University Press.

Santos, B. S. (2005). A globalização e as ciências sociais. São Paulo: Editora Cortez.

Sarlet, I. W. (2005). Dimensões da Dignidade: Ensaios de Filosofia do Direito e Direito Constitucional. Porto Alegre: Livraria do Advogado.
Savaris, J. A. (2008). O processo de reformas da Previdência Social no Brasil como subversão da lógica do desenvolvimento progressivo dos direitos humanos econômicos, sociais e culturais. En Cambi, E. et al (organizadores). Direitos Fundamentais Revisitados, Curitiba, 2008.

Savaris, J. A. (2011). Uma teoria da decisão judicial da Previdência Social: contributo para superação da prática utilitarista. Florianópolis: Conceito Editorial.

Scheffler, S. (1998). Consequentialism and its critics. New York: Oxford University Press.

Sen, A. (Abril de 1985) Well-being, Agency and Freedom: The Dewey Lectures 1984. The journal of Philosophy, 82, 4, 169-221.

Silva, V. A. S. "Taking from the poor to give to the rich: the individualistic enforcement of social rights". Disponível em : <http://www.enelsyn. gr/papers/w13/Paper\%20by\%20Prof.\%20 Virgilio\%20 Afonso\%20 da\%20Silva.pdf $>$. Acesso em: 26 jan. 2012.

Sztajn, R. (1998). Notas de análise econômica: contratos e responsabilidade civil. Revista de Direito Mercantil, 111, p. 9-28.

Tejada, J. T. (2011). Los Derechos Sociales en el contexto de la globalización. Teoría \& Derecho. Revista de Pensamiento Jurídico, 9, 147-162.

Villey, M. (2003). Filosofia do Direito: Definições e fins do direito; os meios do direito. São Paulo: Martins Fontes.

Vita, Á. (1993). O lugar dos direitos na moralidade política. Lua Nova. Revista de Cultura e Política, 30, 30, 5-34.

Vita, Á. (2008). Liberalismo Igualitário, sociedade democrática e justiça internacional. São Paulo: Martins Fontes.

Vita, Á. (2000). A Justiça igualitária e seus críticos. São Paulo: Unesp.

Weber, M. (1993). Ciência e Política: Duas Vocações. São Paulo: Cultrix. 